\title{
ENTRELAÇANDO PARTICIPAÇÃO INFANTIL ÀS PRÁTICAS DEMOCRÁTICAS: UM (RE)ABITAR A EDUCAÇÃO INFANTIL *
}

Fabiana Oliveira Canavieira

Apenas uma forma de ler: abrindo a casa com as chaves de leitura

Cumprir função sociopolítica e pedagógica requer oferecer as melhores condições e recursos construídos histórica e culturalmente para que as crianças usufruam de seus direitos civis, humanos e sociais e possam se manifestar e ver essas manifestações acolhidas, na condição de sujeito de direitos e de desejos (BRASIL, 2009, p. 6).

Nossas escolhas e aproximações teóricas são, a meu ver, pura idiossincrasia. A justificativa é cumprir um ritual que visa articular as preferências teóricas a uma relevância acadêmica, epistemológica e até produtivista, que, ainda assim, são pessoalidades discursivas, ideológicas e/ou contextuais. Parto dessas afirmações para enfatizar que neste artigo faço escolhas que visam pontuar a parcialidade desta pesquisadora e de minha forma de ler o tema em questão, tal qual realizei na pesquisa de Doutorado (2019).

É Foucault (1999) quem enfatiza acerca da importância do uso de uma "caixa de ferramentas" para leitura e compreensão de discursos teóricos, dentre outros. Como, nesse momento, não tenho pretensões de contribuir com a formação de "caixas" teórico-metodológicas, é pertinente partilhar, ao menos, as chaves de acesso ao tema, para que cada leitora/leitor percorra os fios, localize os nós e chegue aos entrelaçamentos propostos, tendo nesta pesquisadora uma guia que aponta possibilidades de caminhos e não como aquela que direciona o caminhar.

*DOI - 10.29388/978-65-86678-02-4-0-f.185-202 
A temática da participação infantil é a chave de entrada no debate em questão; primeiro, porque foi por onde iniciei a construção da pesquisa do Doutorado; segundo, porque é uma temática cara e pertinente aos estudos do campo da Sociologia da Infância e, terceiro, mas não menos importante, porque foi e é uma preocupação político - pedagógica. Assim, é partindo dela que começo a tecer e deslindar uma trama que, por vezes, creio que fui eu mesma quem criei, para me enrolar. Mas, às vezes, penso como Nobert Elias (1994), que se trata de "fios com nós invisíveis", ou seria mais coerente afirmar, invisibilizados.

Não é fácil defender a temática da participação infantil como parte de um debate político democrático mais amplo do que o educacional, não apenas pedagógico, ou meramente teórico, mas significando afirmar que as crianças são capazes de uma ação política consciente. Para tanto, é preciso enfatizar o que estou defendendo como tal. De pronto, trata-se do exercício de uma cidadania ativa, consciente e capaz de gerar atos e fatos reais nos quais as crianças são protagonistas, mas não só, que suas ações influenciam no contexto social de suas vidas e das adultas e dos adultos à sua volta. Ou seja, não se trata de uma participação infantil consultiva, mas deliberativa, a qual pormenorizo na tese. Esse entendimento se inscreve dentro de uma visão políticofilosófica democrática, por isso será ela a defendida.

Há mais de uma forma de ler o tema da participação infantil; a partir de meus estudos, passei a classificar as portas de entrada e "chaves de leitura" da seguinte maneira:

- Por via da conquista de direitos;

- Pela perspectiva sociológica;

- Por via das pedagogias ativas como perspectiva didático-metodológica;

- Pelas antigas abordagens pedagógicas libertadoras;

- Como forma de socialização ampliada, a exemplo da participação das crianças em comunidades tradicionais,

- Pela perspectiva política. 
Boa parte dos estudos que privilegiam o tema ampara-se na perspectiva sociológica, mais precisamente, filiam-se ou usam os referenciais da Sociologia da Infância, conforme dados levantados e organizados em Canavieira $(2017 ; 2019)$. Esses estudos são frutos de pesquisas de Mestrado e Doutorado em Educação e fundamentam-se na defesa da categoria de ação social das crianças, entendidas como atrizes/atores sociais e sujeitos de direitos, perspectivas que se entrelaçam a partir dos marcos legais internacionais e nacionais de defesa dos direitos civis, humanos e sociais das crianças. Entre eles, a garantia do direito das crianças de participação, que, junto ao direito da organização coletiva ${ }^{1}$, potencializam a ação política delas, mesmo que não sejam assim entendidos.

Tais pesquisas articulam as duas primeiras perspectivas (pontuadas acima) como inseparáveis e culminam com a terceira: a via de leitura da participação pelas pedagógicas ativas como perspectiva didático-metodológica, ou, como teóricos contrários a essa abordagens ${ }^{2}$ denominam, neoescolanovismo, sendo concretizada por via de práticas pedagógicas em que as crianças participam ativamente de diferentes formas, visando a aprendizagens específicas. Ou ainda, pelo debate da política educacional referente à gestão democrática e às práticas participacionistas que passam a incluir as crianças.

Na pesquisa intitulada $O$ fim quem dá são as crianças, e, às vezes, não tem fim: práticas e concepções democráticas na educação infantil (CANAVIEIRA, 2019), depois de problematizar as formas com que li e compreendi os estudos acerca da participação infantil, articulo as últimas três vias ou perspectivas de leitura e entendimento dessa categoria: pela via da filosofia política; podendo ser entendida também como socialização ampliada, ou seja, de participação direta das crianças nos contextos sociais e pela pedagogia dialógica e libertária de Paulo Freire. A partir do entrelaçamento dessas outras três perspectivas, que não são as mais usuais nas pesquisas encontradas, defendo que as crianças são capazes de se inserirem no contexto de uma sociedade democráti-

\footnotetext{
${ }^{1}$ Conforme Convenção dos Direitos das Crianças da ONU - 1989.

${ }^{2}$ MARSÍGLIA, 2011; JACOMELI; ARCE, 2012.
} 
ca se as instituições de Educação Infantil tiverem a intencionalidade político-pedagógica de assim o fazerem. Também aponto na pesquisa como algumas práticas educativas democráticas que envolvem as crianças já vêm ocorrendo nas instituições de Educação Infantil municipais da cidade de São Paulo, desde a primeira gestão municipal do Partido dos Trabalhadores à frente da prefeitura desta cidade, em 1989.

\section{Quando as leituras não respondem: questionando as formas de habitar os estudos da infância}

Construir uma estrutura de pensamento e, a partir dela, textos, é uma forma de habitar (HEIDEGGER, 1951), de ter uma morada. Constrói-se essa habitação quando se edifica, tijolo a tijolo, através de estudos, as filiações teóricas, as incorporações metodológicas, as formas de assinar e demarcar a autoria no projeto de construção. $\mathrm{O}$ pensamento, a linguagem, a escrita, são, nesse sentido, lugares onde se habita, visto que os construímos. "Habitar seria, em todo caso, o fim que se impõe a todo construir. Habitar e construir encontram-se, assim, numa relação de meios e fins. (...) Construir não é, em sentido próprio, apenas meio para uma habitação. Construir já é em si mesmo habitar" (HEIDEGGER, 1951, p. 1).

Desde os meus primeiros passos como estudante e pesquisadora, tenho habitado a Pedagogia a partir da Sociologia, referenciada primeiro no Marxismo, depois nos estudos de Pierre Bourdieu, para enfim adentrar a Sociologia da Infância e a partir dela me encontrar com Antonny Giddens; na Sociologia compreensiva de Weber e no Interacionismo Simbólico, com George Herbert Mead ${ }^{3}$. Todavia, essa morada, que até há pouco tempo era um lugar confortável, deixou de ser. A meus olhos, parte dela (da Sociologia da Infância) parece habitar a casa - da metáfora de G. Bachelard (2003) - sem descer aos porões e

\footnotetext{
${ }^{3}$ Por tratar-se da incursão no pensamento dos referidos autores, não cabe escolher e referenciar apenas uma de suas obras, pois é do conjunto delas que suas "escolas" são formadas. E o destaque está sendo dado às correntes ou escolas sociológicas que tais autores constituíram.
} 
sem incentivar a subida ao sótão, estabelecendo-se no piso intermediário de quem narra, denuncia e critica sem ser radical, ou seja, sem descer as raízes epistemológicas e sem provocar a potência da subida, da escalada, da mudança de lugar, da superação do lugar de acomodação.

Isso será sempre assim se não soubermos ocupar toda a casa, se nos mantivermos confinados apenas no espaço intermediário, nesse espaço de experiências imediatas em que se desenrola o que chamamos de vida concreta e de realidade. Se nos deixarmos prender nos andares intermediários, sem habitar o sótão e o porão, perdemos boa parte de nossa própria condição humana, pois, enquanto lá no sótão se dão as experiências imaginárias e da sublimação, é lá no porão que estão as raízes e a sustentação racional da própria casa (VEIGA-NETO, 2012, p. 269).

Explico. Tendo a casa como lugar de acolhimento, a partir das metáforas de Bachelard (2003) e Veiga-Neto (2012), fornece arcabouços para que eu passe a questionar o espaço da democracia e da ação política de meninas e meninos em seu processo educacional. A Educação Infantil brasileira, tão influenciada política e pedagogicamente, nos últimos quinze anos, pelas matrizes da Sociologia da Infância (CANAVIEIRA, 2010), tem acompanhado a preocupação da área com a defesa da intencionalidade democrática como pressuposto da centralidade das crianças em seu processo educativo e do protagonismo de sua participação em processos ampliados de tomada de decisões?

Infelizmente, não há nos campos da Sociologia da Infância e da Pedagogia da Infância no Brasil muitos referenciais que lancem luz se seria legítimo ou não falar de um agir político de crianças tão pequenas e qual o papel da instituição educativa. Ou que auxiliem nas reflexões a respeito dos seguintes questionamentos: cabe a participação infantil na vida democrática? De que forma? Ou melhor, no que diz respeito à participação infantil na vida democrática, como podem as crianças tomarem parte do que historicamente é concebido como algo do qual não fazem parte (a vida política)? Como a Educação Infantil ga- 
rante a cidadania ativa das crianças pequenas? São perguntas para as quais não achei respostas nos estudos da Sociologia da Infância.

O que há é uma participação infantil sendo tratada como algo institucionalizado pelos espaços educacionais, na gestão do tempo-espaço das crianças nas instituições, na transposição metodológica do currículo e, raramente, em assembleias de turmas e Conselhos de Crianças, em detrimento de uma participação das crianças que tenha valor em si mesma, que seja operada para outros fins (que não apenas os pedagógicos), que seja a organização coletiva das/pelas crianças em prol de seus interesses.

Depois da realização da pesquisa com as educadoras da rede de São Paulo (CANAVIEIRA, 2019), passei a me perguntar, se mesmo nessas formas institucionalizadas todas as crianças participam da mesma forma? Os teóricos da Sociologia da Infância que discorrem acerca do tema ${ }^{4}$ afirmam haver diferentes níveis e escalas de participação. Será que crianças negras, bebês e meninas deliberam tanto quanto os meninos brancos? Seria preciso viver as formas institucionalizadas de participação para responder a essas questões. E se há segregações na forma de participação, ela não pode ser democrática.

Dentre os vários estudos em meio à vasta produção de pesquisas filiadas à Sociologia da Infância, são os escritos de três autoras e um autor que contribuem para a discussão da ação política das crianças, tendo-a como parte do debate democrático. A brasileira Kátia Agostinho (2010; 2016); as portuguesas Catarina Tomás (2011; 2017); Gabriela Trevisan (2014) e o inglês Peter Moss (2009; 2013), cada um a sua maneira, por vezes, diretamente como Peter Moss e K. Agostinho, e indiretamente, como as portuguesas que, pesquisando a participação das crianças em contextos ampliados, fora dos muros da instituição educativa (TOMÁS, 2011; TREVISAN, 2015), defenderam um tipo de participação infantil que fundamenta o lugar de transição dos estudos da área; explico a seguir.

\footnotetext{
${ }^{4}$ FERNANDES, 2009; HART, 1992; LANWDSON, 2005.
} 
No que compete especificamente à participação infantil, o conceito que me apraz tomar parte é o definido por Tomás e Gama (2011, p. 3), em que

Participar significa influir diretamente nas decisões e no processo em que a negociação entre adultos e crianças são fundamentais, um processo que possa integrar tanto as divergências como as convergências relativamente aos objectivos pretendidos e que resultam num processo híbrido. A participação é um processo gradual, mas seguro, que se pretende, pela experiência e pela aprendizagem da participação das crianças seja [...] um direito fundamental da infância no reforço dos seus valores democráti$\cos ($ sic.).

Para Gabriela Trevisan, em sua tese de doutorado intitulada "Somos as pessoas que temos de escolher, não são as outras pessoas que escolhem por nós". Infância e cenário de participação pública: uma análise sociológica dos modos de codecisão das crianças na escola e cidade (2014), a pesquisadora apresenta uma definição de cidadania que contemplaria as crianças como "um conjunto de experiências subjetivas em esferas públicas e privadas, em que os cidadãos constroem identidades coletivas e individuais, participando e influenciando essa esfera (p.10)". Há em seus escritos passagens em que ela tenciona a participação política das crianças na escola e na cidade, como espaços socializadores da dimensão política, auxiliando as crianças a obterem diferentes fontes de conhecimento, de construção de identidade, de desenvolvimento de competências de negociação, de liderança e de influência como processos políticos de tomada de decisão por parte delas próprias.

A ideia de criança como ator politicamente competente parece ter sido, nos últimos anos, alvo de interesses de investigação em diferentes domínios, não sendo a Sociologia da Infância uma exceção. No entanto, parece também ser pertinente recolocar algumas premissas, sobretudo no que a participação das crianças 
diz respeito, em cenários promotores de codecisão. Estes serão entendidos, aqui, como os mais genuinamente próximos da construção da ideia de cidadania infantil, assumindo as crianças como competentes para analisarem situações, formularem argumentos, construírem prioridades e, finalmente, construírem decisão juntamente com os adultos nos contextos em que se inserem. (TREVISAN, 2014, p. 8, grifo meu).

Os conceitos das autoras portuguesas Tomás (2011) e Trevisan (2015), assim como o de Peter Moss, que apresento a seguir - justificando porque é importante falar de práticas democráticas na Educação Infantil -, têm em comum a busca pelos valores democráticos, ou a afirmação da importância da presença destes na prática educativa com crianças pequenas. Todavia, nem mesmo essa autora e esse autor. que se dedicaram a dizer que valores são esses. De qual democracia es tão defendendo e como garantir práticas democráticas junto às crianças, além da "mera" participação. O que Moss (2009) afirma, para início desse processo de "democratização" na Educação Infantil, é a clareza da intenção, ou da escolha consciente pelo exercício da democracia na vida cotidiana das crianças. Para ele, a justificativa para defesa das práticas democráticas não se restringe ao processo educacional com um fim em si mesmo, mas para o bem da própria democracia.

Por que práticas democráticas são tão importantes, no geral e na educação infantil? A necessidade pode ser posta em poucas palavras. Participação democrática é um critério importante de cidadania: é um meio pelo qual crianças e adultos podem se envolver com outros na tomada de decisões que afetam eles mesmos, grupos dos quais eles são membros e a sociedade como um todo. É também um meio de resistir ao poder e à sua vontade de governar, e às formas de opressão e injustiça que emergem do exercício descontrolado do poder. Por fim, mas não menos importante, a democracia permite que a diversidade prospere. Ao fazer isso, oferece o melhor ambiente para a produção de pensamentos e práticas novas. (MOSS, 2009, p. 419, grifos meus). 
Os fundamentos dos princípios democráticos, os tipos de cidadania, a crítica aos modos de cidadania na sociedade contemporânea, as relações de poder e formas de governo são tematizações pouco usuais na área dos estudos da pequena infância, mesmo na Sociologia da Infância que cerca o tema, não o adentra em profundidade, não debatendo o que seria subsunçor à defesa da participação infantil, como parte do entendimento da participação social, que é inerente às sociedades democráticas. Sendo assim, por essas lacunas e ausências, foi necessário buscar fundamentos na filosofia política e nas ciências políticas, para que pudesse fazer a defesa radical da cidadania ativa das crianças, da participação infantil como ação política destas. Apresento, então, minha breve incursão nos estudos dessas áreas.

\section{Transcendendo a filiação da área estudo: descendo aos porões}

Pensar com a Filosofia é manter-se no lugar de quem pergunta, de quem reflete a partir das e nas lacunas, na ausência de respostas como domínio das verdades. É também reverter a ordem de construção dos discursos e das narrativas comuns aos estudos inscritos nas Ciências Sociais, em que se parte do "estabelecido" como desigualdades, opressões, injustiças, indiferenças e individualismos, para afirmar: igualdade de diretos; direito às diferenças; justiça social e o fim das formas de desigualdades e opressões. Os valores democráticos de liberdade, igualdade, justiça, pluralidades, solidariedades e emancipação seriam os lugares de chegada, quando para alguns filósofos como Hannah Arendt e Jacques Rancière (1996), são os lugares de partida, quando se caminha com a Filosofia.

Partindo da defesa de que as crianças são capazes de organização coletiva, de escolherem, opinarem, decidirem e negociarem seus interesses e desejos, e ainda, que são empáticas e solidárias, que podem ser autônomas, críticas e respeitosas das diferenças, diversidades e pluralidades socioculturais, me cabe seguir levantando questionamentos acerca de como temos visto e garantido tais potencialidades. Somos democráticas nas relações cotidianas que incluem as crianças? Como 
as crianças exercem sua cidadania nos espaços em que atuamos? A respeito do que as crianças deliberam? Quais espaços-tempo garante-se para sua manifestação de opinião, organização coletiva espontânea e para suas formas de negociação?

Talvez tenhamos ficado presas/presos no dualismo anacrônico do pensamento educacional de J.J.Rousseau (1995), em que, ao mesmo tempo em que dedica um olhar especial e particular à criança e reivindica para ela o direito de felicidade na própria infância, enseja uma educação distante dos livros e castigos, preocupada em garantir uma certa lentidão ao aprendizado, e que esse seja construído a partir das experiências, dos jogos, do trabalho manual, partindo progressivamente dos sentidos até atingir a consciência, quando então se daria a educação moral (SINGER, 2010). Rousseau também defende que, para educar o seu Emílio, é necessário fazer a escolha entre formar o homem ou o cidadão.

Em sua obra recomendará primeiro formar o homem natural, que está na criança, e não formar o homem social, o cidadão. A Pedagogia moderna seguiu os conselhos e, quando tem se proposto formar o homem social, o cidadão, tem insistido na formação dos valores, hábitos e comportamentos que ornamentam o homem natural. Os bons sentimentos, a vontade esclarecida, o caráter controlado, os apetites domesticados. É essa a dimensão da cidadania trabalhada na relação pedagógica (ARROYO, 2010, p. 75).

Pensando com Jacques Rancière (1996), lembro que quando abordo o tema da cidadania, colocando-o em relação com o campo educacional, não estou com isso querendo afirmar que a educação é uma condição para a ação política, ou seja, não há uma ideia de capacitismo e de etarismo como pré-requisitos para a cidadania ativa das crianças. Rancière (1996), ao travar sua discussão referente à emancipação e igualdade, temas inerentes ao debate democrático - mas também, da forma como o autor entende e defende a educação não transmissiva -, afirma que não vê na articulação dos conceitos de educa- 
ção-cidadania o mote para pautar a necessidade de uma preparação para o exercício democrático, mas pronuncia conter na educação a potencialidade que demonstra ser a experiência educacional em si mesma um movimento político que pode e deve ser democrático.

Quando um número crescente de mulheres pesquisadoras passa a pautar e ressignificar o conceito de cidadania para contemplar grupos minoritários (MOUFFE, 2003; YOUNG, 2006; ARAÚJO, 2007), elas passam a considerar, mesmo que de forma incipiente, o que viria a ser o exercício da cidadania pela perspectiva das crianças. Até o início do século XXI, era comum, até no meio educacional, tratar as crianças como cidadãos do futuro, um vir-a-ser-cidadão (FERNANDES, 2009). A relação do exercício da cidadania com a capacidade de exercer o voto, como direito e dever, era automática, e só de posse da inserção dentro da lógica eleitoral seria possível a vivência da cidadania plena. Sendo assim, só aos adultos estava outorgado esse direito.

Como mencionado antes, assim como há diferentes maneiras e níveis de participação, parece haver diferentes formas de compreender e denominar cidadania, que pode ser entendida como cidadania plena, universal, ativa, individualista e até cidadania íntima (TREVISAN, 2017 , p. 2) Na contemporaneidade, estabeleceu-se uma relação forte entre cidadania e o campo dos Direitos Humanos, como uma base ampliada de ressignificação desse conceito, afastando-o do uso "tradicional”. Uma definição formal desse conceito, com a qual dialogo adiante, é apresentada por Benevides (1994).

Na teoria constitucional moderna, cidadão é o indivíduo que tem um vínculo jurídico com o Estado, é o portador de direitos e deveres fixados por uma determinada estrutura legal (Constituição, leis) que lhe confere, ainda, a nacionalidade. Cidadãos são, em tese, livres e iguais perante a lei, porém súditos do Estado. Nos regimes democráticos, entende-se que os cidadãos participaram ou aceitaram o pacto fundante da nação ou da nova ordem jurídica. (p.07) 
Mesmo sem um panorama aprofundado dos usos e conotações do conceito de cidadania, é possível evidenciar que se trata de um campo em disputa, e que as crianças e seus defensores são agentes que travam uma batalha por posição dentro dele. Parece-me que, para participarem como cidadãs em nossa sociedade, as crianças precisam ser vistas também como agentes políticos, como pontuam Trevisan (2015) e Qvortrup (2010).

Esse último autor apresenta sólidas ponderações acerca do tema, em seu artigo Infância e Política (QVORTRUP, 2010), em que faz o movimento contrário; afirma que, entre as disciplinas acadêmicas do campo das Ciências Sociais, a que mostrou menos interesse pelos estudos da infância tinha sido a Ciência Política, por isso a dificuldade em encontrar referências dos temas da cultura política na intersecção com a Educação Infantil. $\mathrm{O}$ autor anota que a curiosidade que as Ciências Políticas poderiam ter pelas crianças se concentraria na socialização política. Essa ressalva me fez pensá-la a contrapelo, por que a área dos Estudos da Infância também não buscou diálogo com as Ciências Políticas e a Filosofia Política? Talvez porque ainda não tenha se atentado para o debate sobre a socialização política das crianças?

Buscar por essas respostas significou descer aos porões, não necessariamente uma mudança de casa, como achava a princípio. As raízes estavam lá entrelaçadas (entre Sociologia e Filosofia), mas era mais confortável habitar o lugar conhecido, mobiliado e já povoado, do que partir em uma busca solitária ao lugar mais "insalubre", ainda assim, eu achava que alguém devia descer, e eu tentei.

Quando iniciei os estudos sobre Democracia, no auge da crise política e do golpe à democracia brasileira, em maio de 2016, o fiz a partir da relação do tema com a Educação de uma forma geral, primeiro com Gert Biesta (2013), depois com Jan Masschelein e Maarten Simons (2014), e por esse caminho passei a pensar em como retomar os conceitos e fundamentos clássicos DE Democracia para pensar a participação infantil, deparando-me com um mar de possibilidades. Busquei pelo caminho que acreditava mais seguro e usual na temática democrática, pelos fundamentos sociopolíticos, com Boaventura de Sou- 
sa Santos (2007 e 2019) e Noberto Bobbio (1989). Mas me ocorreu o seguinte pensamento: se, de antemão eu já havia entendido que a Sociologia da Infância não seria a matriz teórica principal da pesquisa, como poderia fundamentar a parte acerca dos conceitos Democráticos pela Sociologia e a outra pela Filosofia? Foi nesse momento que optei pela Bricolagem como abordagem metodológica que permitia uma composição multireferencial. Agora cabia pensar tudo isso em contexto real, ou melhor, praxiológico.

\section{Por entrelaçamentos entre conceitos e práticas democráticas: subindo ao sótão}

Não acredito ser prudente apresentar dados de pesquisa sem demonstrar o percurso de como eles foram construídos. Na perspectiva teórico-metodológica que defendo, o caminhar é mais importante do que o ponto de chegada; acredito que dados recortados não falam por si só, e podem, ao contrário, falarem contra si, e contra nós! Todavia, cabe-me afirmar que busquei por experiências educativas reais, brasileiras e de instituições públicas municipais que operassem com concepções e práticas democráticas na educação de crianças de 0 a 6 anos de idade, para realização da pesquisa do doutorado. Felizmente as encontrei na cidade de São Paulo. O que não significa que dei conta de abarcá-las em sua inteireza. O que nunca foi o objetivo da pesquisa, que tinha como uma de suas finalidades evidenciar a existência dessa realidade para além do contexto geopolítico no qual elas se situam.

Antes mesmo da realização da pesquisa empírica, já tinha conhecimento da realização de práticas como: assembleia de crianças; cortejo das crianças pela cidade e ocupação de praças públicas para realização de desenho e para brincarem - territorialização da cidade pelas crianças; e, por fim, os conselhos de crianças em algumas instituições municipais paulistanas. De posse dessas informações iniciais, por via da militância social dos fóruns de Educação Infantil e das redes sociais, a pergunta que passei a fazer era: quando essas práticas iniciaram? Por quais motivações? Onde e como elas eram fomentadas? 
Durante o exame de qualificação do projeto de tese, foi levantada a hipótese de que tais práticas poderiam ter relação com a gestão de Paulo Freire à frente da Secretaria Municipal de Educação da cidade de São Paulo, na administração de Luiza Erundina (PT), de 1989 1992. E que esse poderia ser o ponto de partida da investigação, e foi. Tendo o seguinte recorte: as três administrações da Prefeitura Municipal da Cidade de São Paulo pelo Partido dos Trabalhadores: Prefeita Luiza Erundina; Prefeita Marta (à época) Eduardo Suplicy e do Prefeito Fernando Haddad; situando a política educacional oficial por via dos documentos, programas e projetos da SME, mas, principalmente, pela fala das nove colaboradoras da pesquisa ${ }^{5}$ por meio do método das entrevistas compreensivas, procurando por uma política educacional democrática direcionada à Educação Infantil.

As vozes e a experiência das educadoras colaboradoras da pesquisa narram as práticas democráticas que almejava encontrar. tais práticas extrapolam a perspectiva da ideia de gestão democrática realizada apenas por adultos, em que o espaço-tempo escolar-educacional permanece inalterado. As práticas democráticas alteram o espaçotempo das instituições e transversalizam o currículo com a discussão de temáticas de gênero, raça, empoderamento feminino, questões ambientais e direito das crianças. Passa pelo incentivo diário à autonomia infantil em várias ações.

Há nas falas e na política, uma ênfase dada à importância da escuta das crianças, como intencionalidade político-pedagógica de construir a Educação Infantil municipal, essa escuta é realizada cotidianamente, mas também em momentos privilegiados, de forma coletiva, nas assembleias de turma (como relatado pela educadora Naime Silva) e nos conselhos de crianças (como pontuado pelas educadoras Márcia Covelo e Margarida Barbosa, cada uma referente a sua instituição). A capacidade de escuta das educadoras e da rede como um todo

${ }^{5}$ Educadoras ligadas à rede municipal paulistana, que participaram colaborando livre e esclarecidamente da pesquisa, sendo elas, as professoras: Naime Silva e Margarida Barbosa; as Supervisoras/Coordenadoras: Shirley $\mathrm{M}^{\mathrm{a}}$ de Oliveira e Renata Dias; as gestoras: Solange O. Ferreira e Márcia Covelo; além das ex-gestoras da Secretaria Municipal de Educação: Sônia Larrubia; Aparecida Perez e Lisete Arelaro. 
tornou-se, até equivocadamente, sinônimo de participação. Digo equivocadamente, pois privilegia o olhar de quem ouve e não de quem se expressa. A participação das crianças nos conselhos para essas educadoras é muito mais do que um procedimento pedagógico, dá-se com o corpo todo, é um exercício de cidadania, uma socialização política que contribui para a construção da subjetividade democrática das crianças.

A democracia é realizada na cidade pelas vozes e pelos corpos em movimento, corpos que participam. A democracia tem sido historicamente uma narrativa masculina - os problemas das mulheres e das crianças ainda não são vistos na sociedade como problemas da democracia, são problemas "despolitizados”, empurrados para a margem do debate democrático. O que há nessa pesquisa é uma democracia feminina e feminista, construída por mulheres e crianças, mesmo que por poucas.

Fiz e faço a defesa de uma Educação Infantil Democrática. De uma democracia ressignificada, construída com e na Educação Infantil, com protagonismo das crianças. Que, para além da democratização do acesso, dos saberes e da qualidade, seja uma democratização das relações e práticas cotidianas. Reapresento a tese defendida como proposição inicial, que a partir da análise dos dados da pesquisa é possível afirmar que as instituições de Educação Infantil podem ser espaços de vivência democrática e do exercício da cidadania infantil, desde que tenham essa intenção.

\section{Referências}

AGOSTINHO, Kátia A. Formas de participação das crianças na Educação Infantil. Tese de Doutorado (Doutorado em Estudos da Criança). Braga (Portugal): Universidade do Minho. 2010.

Caminhos para a participação das crianças na educação infantil. X Anped Sul, Florianópolis, Anais Eletrônicos... Florianópolis, UFSC, 2015. Disponível in: <http://xanpedsul.faed. udesc.br/ arq_pdf/ 425-0.pdf $>$ Acesso em: 17 set. 2016. 
ARAÚJO, Helena C. Cidadania na sua polifonia: debates nos estudos de educação feminista. Educação, Sociedade e Cultura, n. 25, p. 83-16, 2007.

ARROYO, Miguel. Educação e Exclusão da cidadania. In: ARROYO, Miguel; BUFFA, Ester; NOSELLA, Paolo. Educação e cidadania: quem educa o cidadão? 14. ed. São Paulo: Cortez, 2010.

BACHELARD, Gaston. A poética do espaço. São Paulo: Martins Fontes, 2003.

BENEVIDES, M. Victoria de M. A cidadania ativa: referendo, plebiscito e iniciativa popular. 3. ed. São Paulo: Ática, 2003. . Cidadania e Democracia. Lua Nova (online). n. 33, p. 5 - 16, 1994.

BIESTA, Gert. Para além da aprendizagem: educação democrática para um futuro humano. Belo Horizonte: Autêntica, 2013.

BRASIL, Conselho Nacional de Educação. Resolução nº 05 da Câmara de Educação Básica que estabelece as Diretrizes Curriculares Nacionais para Educação Infantil. Brasília: MEC, 2009.

BOBBIO, Norberto. O futuro da democracia: uma defesa das regras do jogo. 4. ed. Rio de Janeiro: Paz e Terra, 1989.

CANAVIEIRA, Fabiana O. A Educação Infantil no olho do furacão: o movimento político e as contribuições da Sociologia da Infância. Dissertação de Mestrado. Campinas: Faculdade de Educação da UNICAMP, 2010.

. "O fim quem dá são as crianças, e, às vezes, não tem fim ": concepções e práticas democráticas na Educação Infantil. Tese (Doutorado em Educação). Porto Alegre: Faculdade de Educação da UFRGS, 2019.

CANAVIEIRA, Fabiana O.; BARBOSA, Maria Carmen S. Participação Infantil e debate democrático: aproximações pelo campo da educação infantil. Revista Zero-a-seis. v. 19, n. 36, p. 361 - 378, 2017. 
ELIAS, Norbert. A sociedade dos indivíduos. Rio de Janeiro: Jorge Zahar Editor, 1994.

FERNANDES, Natália. Infância, Direitos e Participação: representações, práticas e poderes. Porto/Portugal: Edições Afrontamento, 2009. FOUCAULT, Michael. Vigiar e Punir: o nascimento da prisão. Petrópolis: Vozes, 1999.

HART, R. Participação de Crianças: da indicação falsa até a cidadania. UNICEF, 1992.

HEIDEGGER, M. Construir, habitar e pensar, 1954. Disponível em: $<$ www.prourb.fau.ufrj.br/jkos/p2/heidegger_construir,\%20habitar, \%20pensar.pdf> Acesso em: 30 ago. 2017.

LANSDOWN, Gerison. ¿Me haces caso? El derecho de los niños pequeños a participar en las decisiones que los afectan. Cuadernos sobre Desarrollo Infantil Temprano. No. 36s. fundacion Bernard Van Leer, La Haya, Paese Bajo, 2005.

MASSCHELEIN, J.; SIMONS, Maarten. A pedagogia, a democracia, a escola. Belo Horizonte: Autêntica, 2014.

MOSS, Peter. Introduzindo a política na creche: a educação infantil como prática democrática. Revista Psicologia. São Paulo, v.20, no.3, p. 417 - 423, jul./set. 2009.

. Portare le Politiche nei servizi educativi: L'educazione nella prima infanzia come pratica di democrazia. Bologna (Itália): Grupp Nazionale Nidi e Infanzia, 2013.

MOUFFE, Chantal. Democracia, cidadania e a questão do pluralismo. Política e Sociedade, n. 03, p. 11 - 26, 2003.

QVORTRUP, Jens. Infância e Política. Caderno de Pesquisa, v.40, n. 141, p.777 - 792, Set/Dez, 2010.

RANCIĖRE, Jacques. O dissenso. A crise da razão. São Paulo: Companhia das Letras, 1996b. 
ROUSSEAU, J. J. Emílio ou Da Educação (livro primeiro). São Paulo: Martins Fontes, 1995.

SANTOS, Boaventura de S. Renovar a teoria crítica e reinventar a emancipação social. São Paulo: Boitempo, 2017.

. (org.). Democratizar a democracia: os caminhos da democracia participativa. Porto (Portugal): Afrontamento, 2003.

SINGER, Helena. República de Crianças: sobre experiências escolares de resistência. Campinas (SP): Mercado de Letras, 2010.

TOMÁS, Catarina. Há muitos mundos no mundo: cosmopolitismo, participação e direito das crianças. Porto (Portugal): Afrontamento, 2011.

TOMÁS, Catarina; GAMA, Ana. Cultura de (não) participação das crianças em contexto escolar. In: Educação, Território e (Des)igualdades. II ENCONTRO DE SOCIOLOGIA DA EDUCAÇÃO. 2011, Porto, Anais eletrônicos.... Porto, (Portugal), 2011. Disponível em: $<$ http://repositorio.ipl.pt/bitstream/10400.21/1116/1/Cultura\%20de \%20(n\%C3\%A3o)\%20participa\%C3\%A7\%C3\%A3o\%20das\%20crian \%C3\%A7as\%20em\%20contexto\%20escolar.pdf >Acesso em: 03 abr. 2017.

TREVISAN, Gabriela de Pina. Somos as pessoas que temos de escolher, não são as outras pessoas que escolhem por nós. Infância e cenários de participação: uma análise sociológica dos modos de co-decisão das crianças na escola e na cidade. Tese (Doutorado em Educação). Braga: Universidade do Minho, 2014.

VEIGA-NETO, Alfredo. É preciso ir aos porões. Revista Brasileira de Educação. V. 17, n. 50, maio/ago. p. 267 - 282, 2012.

YOUNG, Iris M. Representação política, identidades e minorias. Lua Nova. São Paulo, n.67, p. 139 - 190, 2006. 